\title{
An environmental optimization model for bioenergy plant sizes and locations for the case of wood-derived SNG in Switzerland
}

\author{
Bernhard Steubing ${ }^{1,2 *}$, Isabel Ballmer ${ }^{3}$, Oliver Thees ${ }^{4}$, Léda Gerber ${ }^{2}$, François Maréchal ${ }^{2}$, \\ Rainer Zah ${ }^{1}$, Christian Ludwig ${ }^{5}$ \\ ${ }^{1}$ Swiss Federal Laboratories for Materials Science and Technology (Empa), 8600 Dübendorf, Switzerland \\ ${ }^{2}$ Swiss Federal Institute of Technology (EPFL), 1015 Lausanne, Switzerland \\ ${ }^{3}$ Swiss Federal Institute of Technology (ETHZ), 8092 Zurich, Switzerland \\ ${ }^{4}$ Swiss Federal Institute for Forest, Snow and Landscape Research (WSL), 8903 Birmensdorf, Switzerland \\ ${ }^{5}$ Paul Scherrer Institute (PSI), 5232 Villingen, Switzerland \\ * Corresponding author. Tel: +41 44823 4219, E-mail: bernhard.steubing@empa.ch
}

\begin{abstract}
Bioenergy from woodfuel has a considerable potential to substitute fossil fuels and alleviate global warming. One issue so far not systematically addressed is the question of the optimal size of bioenergy plants with regards to environmental and economic performance. The aim of this work is to fill this gap by modeling the entire production chain of wood and its conversion to bioenergy in a synthetic natural gas plant both with respect to economic and environmental performance. Several spatially explicit submodels for the availability, harvest, transportation and conversion of wood were built and joined in a multi-objective optimization model to determine optimal plant sizes for any desired weighting of environmental impacts and profits.

We find a trade-off between environmental and economic optimal plant sizes. While the economic optima range between $75-200 \mathrm{MW}$, the environmental optima are with $10-40$ MW significantly smaller. Moreover, the economic optima are highly location specific and tend to be smaller if the biomass resource in the geographic region of the plant is scarcer. The results are similar with regards to the effect on global warming as well as with respect to the aggregated environmental impact assessment methods Ecoindicator '99 and Ecological Scarcity 2006.
\end{abstract}

Keywords: Biofuels, Wood energy, SNG, Life cycle assessment, Environmental optimization

\section{Introduction}

Bioenergy from woodfuel has a large potential to substitute fossil fuels and alleviate global warming. At the same time, it is a limited resource, which should be used optimally from the environmental perspective. An important variable determining the sustainability of wood energy production chains, which has not yet been systematically addressed, is the influence of the size of bioenergy plants on the environmental impacts generated along the bioenergy production chain.

The size of a bioenergy plant affects several variables at the plant and production chain levels. At the plant level the size of a bioenergy plant influences the technology choice and configuration and therefore the efficiency of the biomass conversion, the generated environmental impacts as well as production costs. At the production chain level, the size of a bioenergy plant influences mainly the geographical area needed for the biomass supply, which affects the average transport distance and therefore again environmental impacts and costs. If the biomass is more or less equally distributed on a regional scale, the average transport distance could be estimated by a simple radius-surface relationship. However, in countries with large regional differences in biomass availability - either due to geographic factors such as mountains or deserts, or due to variations of regional demand - this relationship may be different.

The aim of our model is to show how these variables affect the environmental and cost performance of bioenergy plants at different plant sizes and locations. We choose the case of 
the production of synthetic natural gas (SNG) from forest wood (mainly residues from the roundwood production and thinning operations) in Switzerland.

\section{Material and Methods}

\subsection{Overall approach}

In order to model the entire production chain of SNG from wood four submodels were designed to model (A) the spatial wood availability, (B) harvest, (C) transport and (D) the conversion to SNG at the bioenergy plant (Fig. 1). Each submodel models the costs as well as environmental impacts based on life cycle assessment (LCA) resulting for its part of the production chain. Data from the submodels is then processed in the optimization model. The latter first chooses optimal technology configurations for the bioenergy plant from a set of potential technologies for each plant size based on a weighting of environmental impacts and profits. Second the environmental and economic performance is calculated for plant sizes from 5-200 MW. Third the optimal plant size is determined and the procedure is repeated for plants in different geographic contexts of Switzerland.

Environmental impacts are assessed with the methods global warming potential (GWP) [1], the Ecoindicator '99 (H/A) (EI'99) [2] and the Ecological Scarcity 2006 (ES'06) [3]. Life cycle inventory has been taken from the ecoinvent database [4].

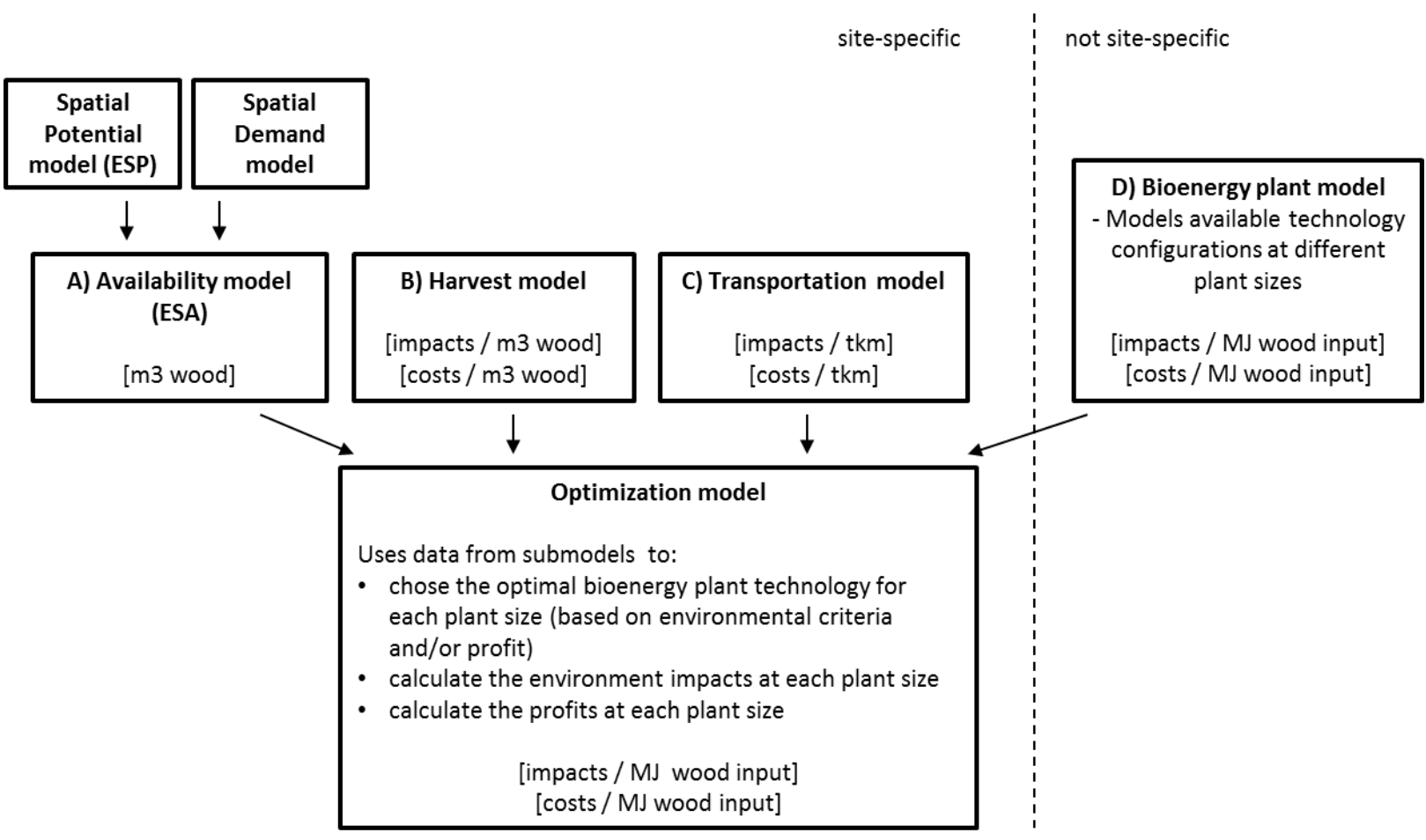

Fig. 1. Methodological approach used

\subsection{Submodels}

\subsubsection{Availability model}

The spatial wood availability model consists of two separate models. The first is the spatial potential model. It derives the effective spatial potential (ESP) of forest fuel based on data from the Swiss national forest inventory (NFI) as well as sustainability criteria such as biological, societal and economic restrictions [5]. The ESP was calculated for two different harvest scenarios, reflecting on the one hand the current situation where approximately 7 million $\mathrm{m}^{3}$ are harvested in total and on the other hand a maximum scenario where 12 million 
$\mathrm{m}^{3}$ are harvested. The maximum scenario involves a reduction of the stock which has been built up during recent decades as the growth of approximately 9.5 million $\mathrm{m}^{3}$ has been higher than the harvested quantities [6]. The maximum scenario could be sustained for about 30 years.

The spatial wood demand model [5] is based on the one hand on a database containing spatially explicit information for automated wood energy installations in Switzerland [7] and on the other hand on the overall demand from households [8], which was spatially distributed according to population density.

The effective spatial availability (ESA) is yielded by subtracting the spatial wood demand from the spatial wood potential.

\subsubsection{Harvest model}

The calculation of the environmental impacts of the harvest is based on ecoinvent data, which includes stand development and forest maintenance as well as the felling and chipping of the wood. The price for forest fuel at the SNG plant site is assumed to be $37 \mathrm{CHF} / \mathrm{b}-\mathrm{m}^{3}$ (bulk cubic meters) [9], excluding transport costs.

\subsubsection{Transportation model}

The transportation model calculates the costs and environmental impacts resulting from the transport of wood chips from the forest to the SNG plant by lorry. Transportation distances from NFI sample points to all plant locations have been calculated along the forest road network and the adjacent street network from Vector25 [10]. The environmental impacts are based on ecoinvent data for a 20-28t lorry. We assume average transportation costs of 6.50 CHF per driven vehicle kilometer ${ }^{1}$.

\subsubsection{Bioenergy plant model}

The conversion of wood to SNG has been comprehensively modeled using different technologies and configurations including directly and indirectly heated fluidized bed gasification systems as well as several alternatives for gas separation [11-13]. Our bioenergy plant model contains the results for these technology configurations with respect to economic and environmental performance. In addition we defined the restriction that more sophisticated technologies, e.g. directly heated oxygen-blown gasification or pressurized indirect gasification may only be chosen for plant sizes greater than $25 \mathrm{MW}$. The bioenergy plant model therefore represents a set of potential technology options for each plant size from which the optimization model can choose the optimal one given the environmental and economic weighting.

\subsection{Optimization model}

An optimization model was implemented in Matlab. It first chooses optimal technology configurations from the bioenergy model for each plant size. The choice is based upon weighted environmental and economic performances. To be able to calculate the economic performance (profit), we must also include the revenues from the sale of SNG as well as the co-products electricity and heat. For the revenues we assume the following prices per MWh:

\footnotetext{
${ }^{1}$ Own calculation based on data from the ASTAG (Swiss Association for Road Transportation: www.astag.ch)
} 
$90 \mathrm{CHF}$ for SNG, $135 \mathrm{CHF}$ for electricity ${ }^{2}$ and $60 \mathrm{CHF}$ for heat. To calculate the environmental impacts we assume a substitution of fossil energy. We expect that SNG is used in natural gas cars (Euro 5 emission standard ${ }^{3}$ ) to replaces petrol driven cars (Euro 5), electricity is used to replace the marginal future Swiss electricity mix which consists of nuclear power (90\%) and power from natural gas combined cycle plants (10\%), and the excess heat from the SNG production is fed into a district heating network to substitute heat otherwise provided by natural gas boilers. Profit and environmental impacts are calculated according to equations (1) and (2):

Profit $=$ Revenues $_{\text {bioenergy }}-{\text { Production } \text { Costs }_{\text {bioenergy }}}$

Env.Imp.net $=$ Env.Imp. bioenergy - Env.Imp. fossil energy

Profit and environmental impacts are calculated for each technology option from the bioenergy plant model. Then a weighted score is calculated for each technology choice based on normalized profits and environmental impacts as well as weighting criteria, as in Eq. 3. The technology with the highest score is then chosen for the specific plant size and location.

Score $_{\text {technology choice }}=$ Env.Imp. normalized $*$ weight $_{\text {env }}+$ Profit $_{\text {normalized }} *$ weight $_{\text {eco }}$

Next, the environmental and economic performance is calculated for plant sizes from $5-200$ MW for different locations in Switzerland. We choose these locations to be close to populated areas to allow for a potential heat use of the plant as well as with the aim to represent the different regions of Switzerland. Sensitivity analysis is performed with regards to weighting criteria as well as wood availability scenarios.

\section{Results}

Fig. 2 shows the average transport distances that are covered to supply SNG plants with wood for different locations and sizes from 5-200 MW for the maximum effective spatial potential (ESP) and the maximum effective spatial availability (ESA) scenarios. It can be observed that the variation of the transport difference at a given plant size is considerable for different locations, especially for larger plant sizes. This effect becomes even more important in the ESA scenario due to the increased scarcity of wood. It should also be noticed that for some locations a simple radius-surface relationship would not be correct to assume (e.g. St. Gallen).

\footnotetext{
${ }^{2}$ Not in all cases electricity is produced. If it is not produced then the same price is paid for the electricity consumption of the plant.

${ }^{3}$ http://europa.eu/legislation_summaries/environment/air_pollution/128186_en.htm
} 

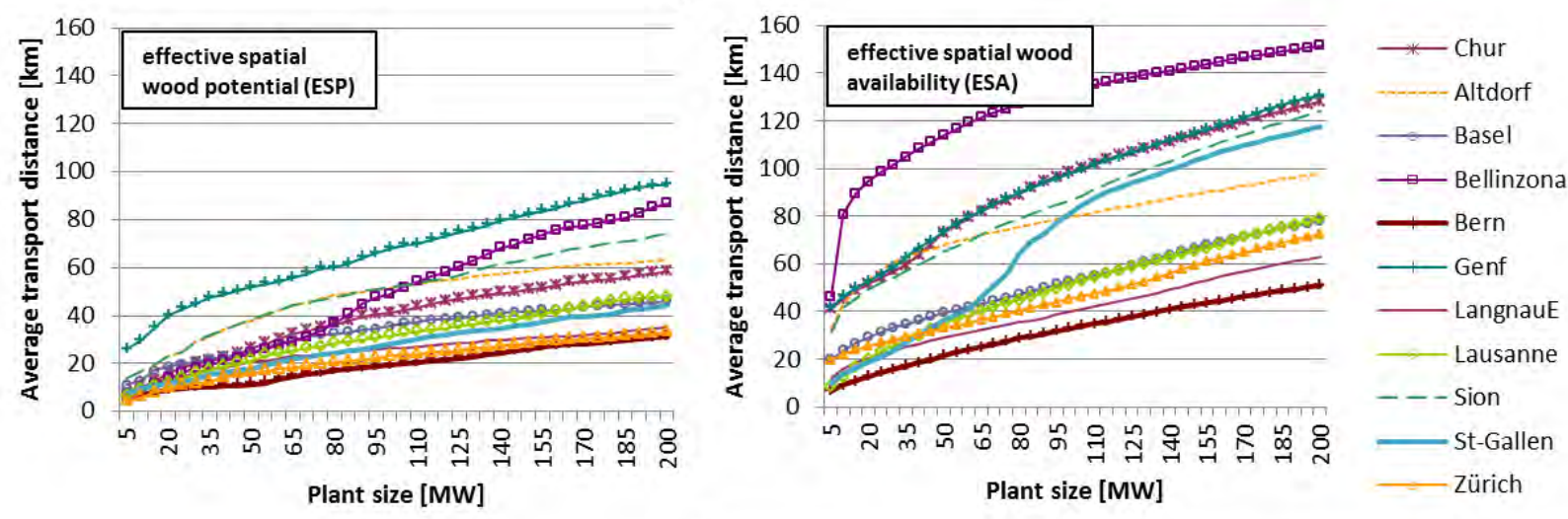

Fig. 2. Average wood transport distances for plant sizes from 5-200 MW for different locations in Switzerland (right: without demand consideration (ESP), left: with demand consideration, both maximum scenario)

Fig. 3 (left and middle) show the economic and environmental performance for a specific SNG plant (Chur) for an equal weighting of profits and environmental performance. First of all, it can be observed that the environmental performance of the system is dominated by the effect of the substitution of fossil fuels through the plant's products SNG and heat. In other words, what really matters is a high wood-to-fuel conversion efficiency, whereas the impacts of the production of the biofuel are rather small. Nevertheless, the impacts of transportation are responsible for the general slope of the environmental performance. Concerning the profits, however, the increased transport distance is more relevant and responsible for the overall decline of profits at large plant sizes. The most important factor for the profits are economies of scale that can be achieved at higher plant sizes due to decreasing production costs. The drastic change at $50 \mathrm{MW}$ is due to a shift in technology with lower production costs as well as a higher SNG efficiency and a lower heat production. As a result of this technology change, profits increase, whereas the environmental performance decreases, which is also due to the fact that the new technology is more sophisticated and more environmental impacts arise during the SNG production. Note that if the wood price (harvest) would increase (or decrease), it would lead to lower (or higher) overall profits and thus influence the plant size at which SNG plants become profitable.

Fig. 3 (right) shows the normalized and weighted performance ${ }^{4}$ over the entire range of 5-200 MW. It can be observed that for an equal weighting of environmental performance and profits, the highest weighted performance is achieved between 20-50 MW for this location. For smaller plant sizes it decreases significantly due to considerably lower profits whereas for larger plant sizes it decreases only slightly.

\footnotetext{
${ }^{4}$ The environmental curve has the opposite shape as in Fig. 3 (left) since negative environmental impacts are avoided impacts and need therefore to be valued positively
} 


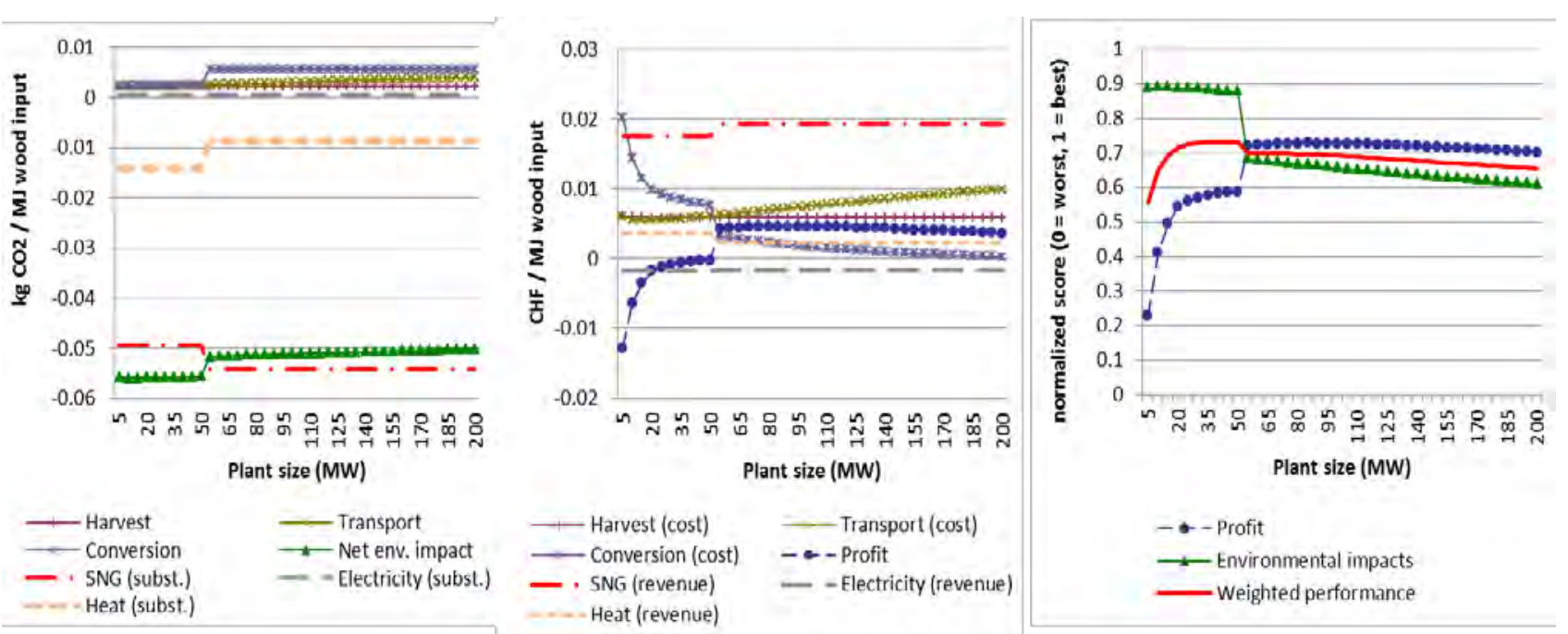

Fig. 3. Environmental impacts, costs and weighted performance for the location of Chur (ESA, equal weighting for profits and environmental performance) $)^{5}$

Since weighting between decision parameters is generally a subjective choice, it is important to understand how the weighting parameters influence the results. In our case, weighting strongly affects the optimal sizes for SNG-plants (Fig. 4). This is due to the fact that environmental performance generally decreases for larger plant sizes (economies of scale are too small or outweighed by increased transport distances), whereas profits generally increase with increasing plant sizes (or have a least a maximum at a higher plant size). This holds also true for a change in wood prices (harvest) since the latter only vertically shifts the profits curve but does not change its shape. Fig. 4 also shows that for a pure environmental weighting (GWP) the optimal plant size converges towards $10 \mathrm{MW}$, while at pure economic weighting the range of optimal plant sizes is large, from $75-200 \mathrm{MW}$, depending strongly on the spatial wood availability. The same results are obtained for an aggregated impact assessment with Ecoindicator'99 and Ecological Scarcity 2006 except that for at a pure environmental weighting plant sizes converge between 20-40 MW.
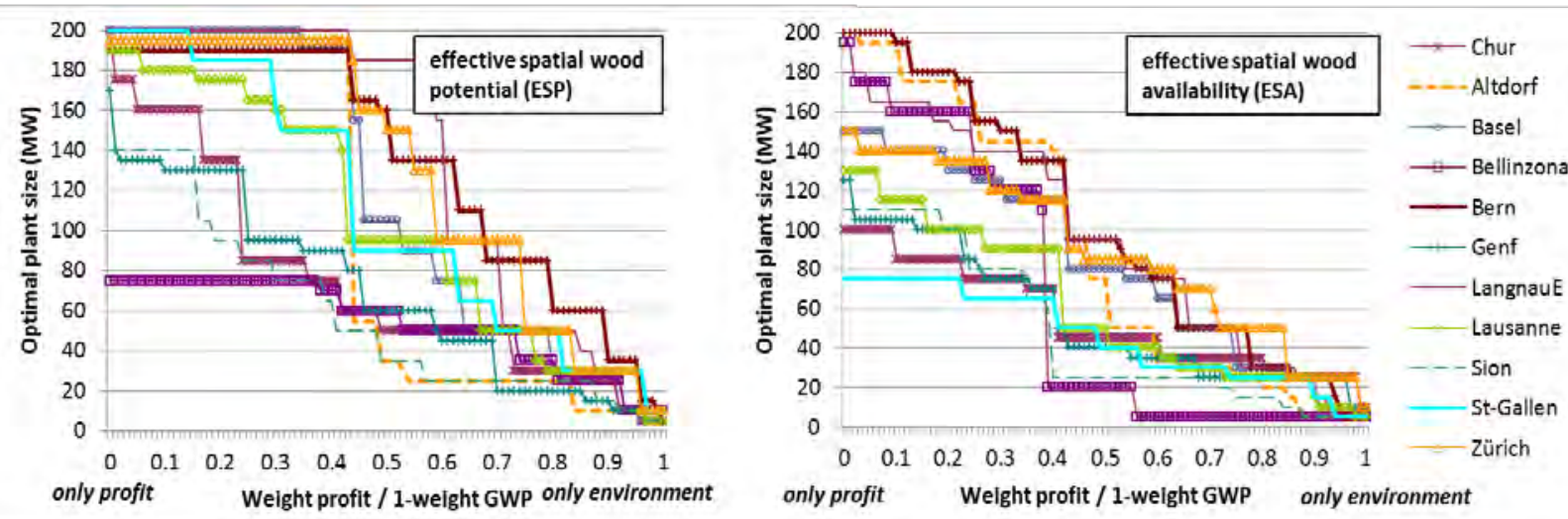

Fig. 4. Relationship of optimal SNG plant scales and weighting of environmental performance (GWP) and profits for different locations

\footnotetext{
${ }^{5}$ At the state of writing $1 \mathrm{CHF}$ was worth 0.78 Euro or 1.04 USD
} 


\section{Discussion}

The sensitivity analysis for the weighting parameters suggests that the final decision must be based on a subjective choice since environmental and economic criteria lead to different optima regarding the plant size (trade-off situation). Even though this conclusion seems to be robust at least for three different environmental evaluation methods, more sensitivity analysis needs to be performed for other model parameters. These include the wood price, sale prices of SNG, electricity and heat (revenues), transport costs, substitution choices (which fossil energy SNG, electricity and heat replace), the heat utilization ratio throughout the year and wood availability. This analysis would also help to understand which factors are the most relevant and need therefore be considered when building SNG plants.

More research is also needed concerning the question whether the results presented here can be generalized for other types of bioenergy plants, e.g. conventional wood district heating systems or combined heat and power plants. An important step missing so far to proceed into this direction is a quantification of the relationships between environmental impacts and plant size for these applications. A recent study however produces empirical evidence that powerlaw relationships could be used for the scaling of environmental impacts at different plant sizes [14].

\section{Conclusions}

We conclude that there seems to be a trade-off between environmental performance and profits regarding optimal plant sizes. While the environmentally optimal plant sizes were found to be between 10 - $40 \mathrm{MW}$, the economically optimal plant sizes range between 75 200 MW. The economic optima are highly location-specific and locations with a lower wood availability also lead to smaller plant sizes from the economic perspective. The results are similar with regards to the impact on global warming as well as two aggregated impact assessment methods. The most important drivers for the economic performance are production and wood transportation costs. The most important drivers for the environmental performance are the effect of the substitution of fossil energy as well as the impacts generated during wood transportation and conversion.

\section{Acknowledgements}

The study is based on results from the master thesis of Isabel Ballmer. We thank the Swiss National Forest Inventory (NFI) and swisstopo for providing the road and forest road network data that have been used within the scope of the thesis. We also like to thank Fritz Frutig (harvesting and transportation model) and Kalin Müller (technical support on GIS) from the Swiss Federal Institute for Forest, Snow and Landscape Research (WSL) for their advices.

\section{References}

[1] IPCC Climate Change 2007: Synthesis Report; IPCC, Intergovernmental Panel on Climate Change: 2007.

[2] Goedkoop, M.; Spriensma, R. The Eco-indicator 99: A damage oriented method for Life Cycle Impact Assessment; PRé Consultants B.V.: Amersfoort, NL, 22. June 2001, 2001; p 132.

[3] Frischknecht, R.; Steiner, R.; Niels, J. Methode der ökologischen Knappheit Oekofaktoren 2006; 28/2008; Bundesamt für Umwelt (BAFU), ÖBU Schweizerische Vereinigung für ökologisch bewusste Unternehmensführung: Zürich und Bern, 2008; p 4. 
[4] Ecoinvent, Ecoinvent, database version 2.2. In Swiss Center for Life Cycle Inventories: Empa, Dübendorf, Switzerland, 2010.

[5] Pampuri, L. A model of the Spatial Potential and Demand of Energy Wood in Switzerland. Master thesis, Swiss Federal Institute of Technology (ETHZ), Zürich, 2010.

[6] Brändli, U.-B., Schweizerisches Landesforstinventar. Ergebnisse der dritten Erhebung 2004-2006. Eidgenössische Forschungsanstalt für Wald, Schnee und Landschaft (WSL) and Bundesamt für Umwelt (BAFU): Birmensdorf, 2010; p 312.

[7] HES Holzenergie Schweiz. www.holzenergie.ch (14.12.2010),

[8] Primas, A.; Müller-Platz, C.; Kessler, F. M. Schweizerische Holzenergiestatistik 2008; Bundesamt für Energie BFE: 2009; p 78.

[9] WVS Zur Holzmarktkampagne 2010/2011: Richtpreise für Energieholz in EnergieholzHackschnitzel zu Beginn der Holzmarktkampagne; Waldwirtschaft Schweiz 2010; p 3.

[10]LFI Schweizerisches Landesforstinventar LFI, Datenbankauszug vom Oktober 2010; Eidg. Forschungsanstalt WSL, Birmensdorf / Digitale Daten aus der Landeskarte der Schweiz, Bundesamt für Landestopographie (DV043730): 2010.

[11]Gassner, M.; Maréchal, F., Thermo-economic process model for thermochemical production of Synthetic Natural Gas (SNG) from lignocellulosic biomass. Biomass and Bioenergy 2009, 33, (11), 1587-1604.

[12]Gassner, M.; Maréchal, F., Thermodynamic comparison of the FICFB and Viking gasification concepts. Energy 2009, 34, (10), 1744-1753.

[13]Gassner, M.; Maréchal, F., Methodology for the optimal thermo-economic, multiobjective design of thermochemical fuel production from biomass. Computers and Chemical Engineering 2009, 33, (3), 769-781.

[14]Caduff, M.; Huijbregts, M. A. J.; Althaus, H. J.; Hendriks, A. J., Power-Law Relationships for Estimating Mass, Fuel Consumption and Costs of Energy Conversion Equipments. Environmental Science and Technology 2011, accepted for publication. 